\title{
CHRONIC THUMB PAIN OF 11 YEARS DURATION: WHAT IT COULD BE?
}

Chitralekha Keisham ${ }^{1}$, Yumnam Lokendra Singh ${ }^{2}$, Heisnam Angamba Singh ${ }^{3}$, Ranjeeta Sapam ${ }^{4}$, Zamzachin Guite ${ }^{5}$

HOW TO CITE THIS ARTICLE:

Chitralekha Keisham, Yumnam Lokendra Singh, Heisnam Angamba Singh, Ranjeeta Sapam, Zamzachin Guite."Chronic Thumb Pain of 11 Years Duration: What it Could Be?". Journal of Evolution of Medical and Dental Sciences 2014; Vol.3, Issue 71, December 18; Page: 15195-15198, D0I: 10.14260/jemds/2014/4043

ABSTRACT: Glomus tumor is a benign tumor arising from the neuromyoarterial plexus concentrated beneath the nail. This glomus body is responsible for regulating temperature and blood pressure. Glomus tumor is particularly distressing to the patient because of the chronicity of symptoms and lack of proper investigation which will help in identifying the tumor at an early stage. The case highlights the presence of chronic pain of 11 years duration especially in relation to the nail apparatus that should arouse the cause to be due to tumor like glomus tumor.

KEYWORDS: Subungual, glomus, tumor.

INTRODUCTION: Glomus tumor is rare benign tumor of glomus cells commonly found in the subungual region. They are also present less frequently in other nail unit region and extradigital sites. It presents with typical triad of paroxysmal pain, cold intolerance and tenderness to palpation on the fingertip.

CASE REPORT: A 32 years housewife presented to skin OPD with long standing complaints of paroxysmal pain of the right thumb for the past 11 years duration precipitated by pressure and cold. The pain was throbbing in nature and even minor trauma to the particular area caused excruciating pain. Pain was non-radiating. There was no history of any repeated trauma or any habit tic involving manipulation of the nail. There was no similar family history. The patient was middle aged and of average built. Her systemic examination was within normal limits. In the local examination, there was loss of contour of the lunula of the right thumb with a bluish discolouration of size $4 \mathrm{~mm} \times 5 \mathrm{~mm}$. Lunula of the right thumb was larger than the other side comparatively. There was longitudinal erythronychia along with distil notching of the nail plate resembling changes like that of Darier's disease (figure 1). Love's test was found to be positive. In this test, the head of a pin is pressed gently against the tender lesion to localize the pain. Ischaemic test was done in which the inflation of the pressure cuff above her systolic pressure made the pain disappear. We did not do the cold sensitivity test. On the basis of the history and clinical examination, a diagnosis of subungual glomus tumor was made. Her blood and urine investigations were normal. Her blood uric acid was also normal. X ray of the hand was done to rule out any bone involvement which was however normal. Due to the patient's economic limitations, MRI was however not done.

The tumor was removed by transungual approach. The nail plate of the right thumb was completely removed after distal block anaesthesia with lidocaine and tourniquet placement which revealed a semi translucent tumour eroding part of the matrix and adjoining nail bed from within. Using a transverse incision $1 \mathrm{~mm}$ distal and parallel to the lunula, the lesion was exposed and removed in toto which revealed a tumour of size $3 \mathrm{~mm}$ by $1 \mathrm{~cm}$. The site was then sutured and proper antiseptic dressing done. The excision biopsy was consistent with glomangioma that showed thin walled vascular spaces surrounded by one or few layers of glomus cells. This glomus cells are 


\section{CASE REPORT}

characterized by abundant pink or pale cytoplasm and oval or round central nuclei. They were also present in groups in a hyaline matrix, nerve fibres and smooth muscle elements scattered amongst them (figure 2). Patient came up for postoperative dressing and stitch removal after 7 days. She also came for follow up after 1 month. There was improvement with the disappearance of pain on touching the thumb and exposure to cold. However she was lost to follow up when advised to come after 6 months.

REVIEW OF LITERATURE: Glomus tumour is an uncommon benign neoplasm of glomus cells, which are modified smooth muscle cells mostly found in arterio-venous anastomoses of the extremities. The normal glomus body is a contractile neuromyoarterial receptor that controls blood pressure and temperature by regulating flow in the cutaneous microvasculature. ${ }^{1}$ Glomus bodies are highly concentrated in the tips of digits, especially under the nail. So, the tumors are usually located in the subungual area. Most lesions are solitary and localized to cutaneous sites. However multiple glomangiomas, have also been described, and may have extracutaneous involvement. They represent $1-5 \%$ of all soft tissue tumours of the hands. Subungual glomus tumour are more prevalent in adult women in the $3^{\text {rd }}$ or $5^{\text {th }}$ decade of life..$^{2}$ It appears as a small solitary nodule located in the hands in up to $75 \%$ of the patients, most of them in the fingers. ${ }^{3}$ It presents characteristically as a paroxysmal excruciating pain, cold intolerance and tenderness to palpation. There can be shooting pain to the forearm and shoulder at times. Sometimes an electromyography may be necessary to rule out coexistent plexopathy or radiculopathy. ${ }^{4}$ Besides this, there can be a number of nail changes in the form of longitudinal split, erythronychia, bluish discoloration of nail bed and median dystrophy of Heller like change.5,6,7 However changes of erythronychia along with distil notching of the nail plate like that of Darier's disease can be present in subungual glomus tumor as seen in our patient.8,9

The treatment for glomus tumors is total excision. Complete excision is curative and necessary to avoid recurrence. The incidence of recurrence after surgery has been reported in the range of $5-50 \%{ }^{10,11,12}$ The standard approach is direct transungual excision as was done in our patient. The other alternative is through a lateral incision.

This case is reported to highlight the presence of chronic pain of 11 years duration especially in relation to the nail apparatus that should arouse the cause to be due to tumor like glomus tumor. The rarity of the tumor as well as the subtle nail changes associated with it may mimick other conditions of the nail apparatus. This may lead to delay in diagnosis which may lead to bone involvement and rarely malignant change. It is also imperative to follow up these patients over a long time even after excision to check for any recurrence. Recurrence is a common problem and is more frequent in skin coloured lesions within the nail matrix region. ${ }^{3}$ Glomus tumors are difficult to diagnose, particularly since they are often small and situated deep in the fingertip. In a patient presenting with a typical triad of symptoms on the fingertip, glomus tumor should be considered in the diagnosis. In addition, ultrasonography or an MRI scan should be performed to ensure proper diagnosis and treatment. Finally, complete surgical excision should be considered as the curative treatment of choice for glomus tumors. 


\section{CASE REPORT}

Figure 1: Lunula showing area of bluish discolouration of size $4 \mathrm{~mm} \times 5 \mathrm{~mm}$ along with reddish discolouration of the nail bed. Distil nail plate showing nicking.

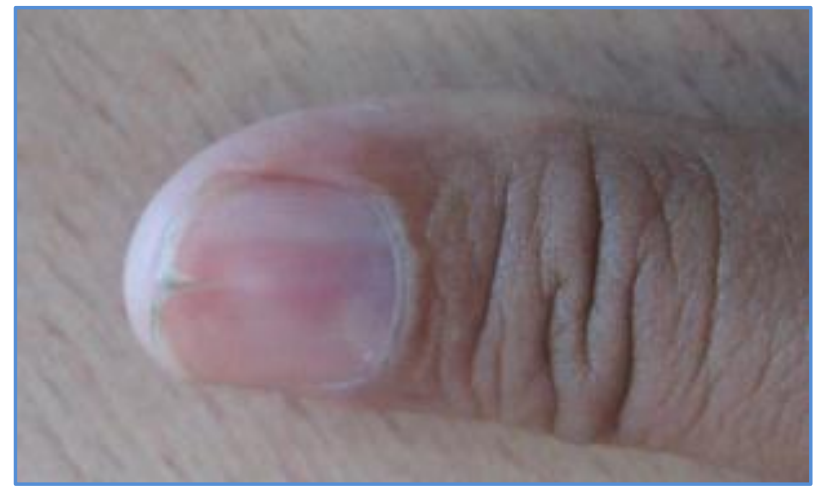

Figure 1

Figure 2: Thin walled vascular spaces surrounded by one or few layers of glomus cells. These cells were as well present in groups in a hyaline matrix, nerve fibres and smooth muscle elements scattered amongst them. (H and E,X100)

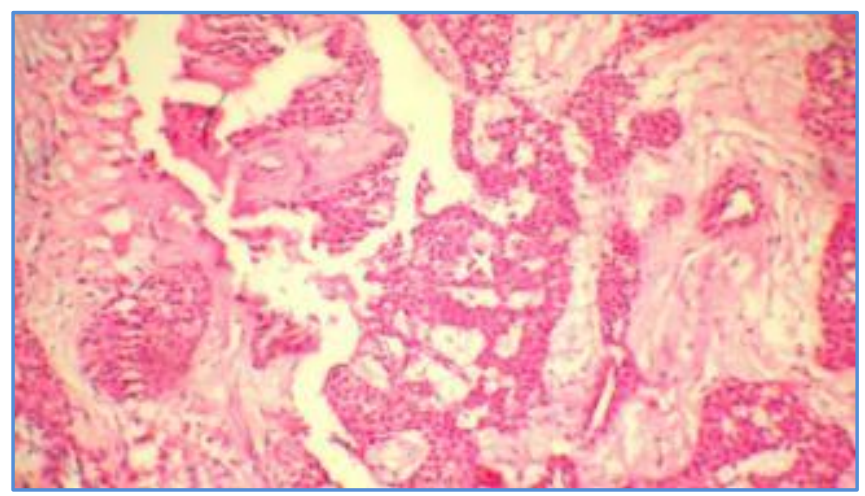

Figure 2

\section{REFERENCES:}

1. Bhaskaranand K, Navadqi BC. Glomus tumour of the hand. J Hand Surg Br 2002; 27: 229-231.

2. Vanti AA, Cucé LC, Chiacchio ND. Tumorglômicosubungueal: estudoepidemiológico e retrospectivo, no período de 1991 a 2003. An Bras Dermatol. 2007; 82: 425-431.

3. Carroll RE, Berman AT. Glomus tumors of the hand: review of the literature and report on twenty-eight cases. J Bone Jt Surg. 1972; 54: 691-703.

4. Waldman S D. Glomus tumor of the shoulder. In. Atlas of uncommon pain syndromes. $3^{\text {rdedn, }}$ Saunder 2014: 90.

5. Lin YC, Hsiao PF, Wu YH, Sun FJ, Scher RK. Recurrent digital glomus tumor: analysis of 75 cases. Dermatol Surg. 2010; 36: 1396-1400.

6. Girisha BS, Shenoy MM, Mathias M, Mohan R. Glomus tumor of the nail unit. Indian J Dermatol. 2011 Sep-Oct; 56(5): 583-584. 


\section{CASE REPORT}

7. Verma SB. Glomus tumor-induced longitudinal splitting of nail mimicking median canaliform dystrophy. Ind J Dermatol Venereol Leprol 2008; 74 (3):257-259.

8. Neerja Puri. A clinical and histopathological study of Darier's disease. J of Pak Association of Dermatologists 2011; 21 (4): 230-234.

9. Burge SM, Wilkinson JD. Darier-White disease: are view of the clinical features in163patients. Jam Acad Dematol. 1992 Jul; 27 (1): 40-50.

10. Carroll RE, Berman AT. Glomus tumors of the hand: review of the literature and report on twenty-eight cases. J Bone Joint Surg Am 1972; 54: 691-703.

11. Van Geertruyden J, Lorea P, Goldschmidt D, de Fontaine S, Schuind F et al. Glomus tumours of the hand. A retrospective study of 51 cases. J Hand Surg Br 1996; 21: 257-260.

12. Vasisht B, Watson HK, Joseph E, Lionelli GT. Digital glomus tumors: a 29-year experience with a lateral subperiosteal approach. Plast Reconstr Surg 2004; 114: 1486-1489.

\section{AUTHORS:}

1. Chitralekha Keisham

2. Yumnam Lokendra Singh

3. Heisnam Angamba Singh

4. Ranjeeta Sapam

5. Zamzachin Guite

\section{PARTICULARS OF CONTRIBUTORS:}

1. MD, Department of Dermatology, Jawaharlal Nehru Institute of Medical Sciences, Porompat.

2. MD, Department of Dermatology, Jawaharlal Nehru Institute of Medical Sciences, Porompat.

3. DNB, Department of Orthopaedics, District Hospital, Churachandpur-795128.
4. MD, Department of Dermatology, Jawaharlal Nehru Institute of Medical Sciences, Porompat.

5. MD, Department of Dermatology, Jawaharlal Nehru Institute of Medical Sciences, Porompat.

\section{NAME ADDRESS EMAIL ID OF THE CORRESPONDING AUTHOR:}

Dr. Chitralekha Keisham, Keishamthong Thangjam Leirak, Imphal-795001.

Email: dr.chitralekhakeisham@gmail.com

Date of Submission: 08/12/2014.

Date of Peer Review: 09/12/2014.

Date of Acceptance: 12/12/2014.

Date of Publishing: 18/12/2014. 